\title{
Technology-Mediated Collaborative Learning: The Bridge21 Activity Model in Theory and Practice
}

\author{
Jake Rowan Byrne, Sharon Kearney and Kevin Sullivan
}

\begin{abstract}
This chapter explores the Bridge21 activity model designed to support the development of an innovative 21 st century learning environment in 2 nd level schools. Over the past ten years, the model has been developed, trialed and tested with over 14,000 students and over 2,000 teachers, both in informal and formal educational scenarios. Research conducted at Trinity College Dublin has evaluated and underpinned the development of this learning model.

The Bridge21 learning model is a pragmatic approach to team-based technology-mediated learning. It is designed to leverage current technology and to release students' potential through a structured move away from individualised, teacher-led learning. Essential elements of the model include: Technology-Mediated, Project-Based, Teamwork and Reflection.

This chapter introduces the Bridge 21 activity model and provides approaches and techniques to those who wish to design Bridge21 learning experiences. It empowers schools to build on what already works well for teachers and students, while creating the space for innovative ideas and alternative approaches to teaching and learning. It presents a shift in focus from the teaching of individual subjects, to the teaching of key competencies and 21st Century learning skills.
\end{abstract}

Keywords: 21C Learning, 21C Skills, Teamwork, Technology-mediated learning, Project-based learning

\section{Introduction: Bridge21 background}

Working and learning in a way that helps students develop a set of skills and knowledge relevant to modern living is a broad aim of many education systems. Approaches to twenty first century technology-mediated learning ("21C learning") and the development of "21C skills" are frequently discussed in educational literature (Ananiadou \& Claro, 2009; Dede, 2007; Fullan \& Langworthy, 2013; Rotherham \& Willingham, 2012; Yelland, Cope \& Kalantzis, 2008). There are various definitions of which skills could be included, but there is a large overlap among them. Definitions of $21 \mathrm{C}$ skills often include the capabilities to: use information and communication technology (ICT) proficiently; access and filter large amounts of information online; work alone or as part of a team; communicate effectively to a wider audience using a variety of digital media; think critically and creatively; and solve problems that do not have a single neatly defined solution (Dede, 2010; Voogt \& Roblin, 2012).

J.R. Byrne $(\square) \cdot$ S. Kearney $\bullet$ K. Sullivan

Centre for Research in IT in Education and School of Education, University of Dublin, Trinity College Dublin, Dublin, Ireland

e-mail: jake.byrne@tcd.ie

L. Daniela (ed.), ***,

DOI 10.1007/979-0-12345-123-1_20,

(C) Springer Science+Business Media New York 20** 
Consistent with these capabilities, Ravitz, Hixson, English and Mergendoller (2012) defined a discrete list of 21C skills, including a list of sub-skills for each. These definitions provide further clarity about the content of each skill category and allow for a measurement of how often students use each skill. They include:

- Collaboration skills,

- Communication skills,

- Creativity and Innovation,

- Critical Thinking,

- Learning with Technology and

- Self-direction skills.

Several of these skills are not necessarily new to the twenty-first century (Silva, 2009); however, the focus on the role of technology within them is new, and they are increasingly relevant to how people work and learn in a digitally-connected, information-rich world (Dede, 2010; Voogt \& Roblin, 2012). Thus, it's argued that educators should emphasise acquiring these skills through curricular integration and aim to develop these skills among students in a manner that is deliberate and effective (Dede, 2010; Voogt \& Roblin, 2012; Spiro, Coulson, Feltovich \& Anderson, 2004).

The phrase "21C learning" refers to approaches to education which aims to integrate $21 \mathrm{C}$ skills into student learning, in both process and outcome. These approaches often include ideas such as constructivism, teamwork, problem solving and working and learning with modern technology. In fact, many of the pedagogical approaches used to develop them have been promoted over the past century by people like Vygotsky (1978) and Piaget (1964). Despite the development of theoretical approaches to integrating technology into the curriculum and developing students' $21 \mathrm{C}$ skills, there continues to be a lack of practical, pragmatic pedagogies for integrating technology and developing these skills in students' educational experiences (Conneely, Lawlor \& Tangney, 2013; Donnelly, McGarr \& O'Reilly, 2011). As Bruenig (2005) argues, "educational theories are theory rich but experience poor...lacking in practical information about instructional strategies" (p. 107).

The goal of this chapter is to address this issue by providing practical information and instructional strategies, while also building on a rich theoretical foundation. It presents the Bridge 21 model of teaching and learning - a content agnostic approach which incorporates technology-mediated learning, collaborative learning, and project-based learning. Underpinned by a social constructivist ethos (Vygotsky, 1978), the Bridge21 model integrates these ideas in a structured manner. It was first developed in an out-of-school setting, and now has more than 10 years of practical and instructional experience.

Bridge 21 is not only a pedagogical model, but an ongoing empirical research project, following a design based research approach (Wang \& Hannafin, 2005). It has been used across a wide range of subject areas both in the formal and informal learning environments: Digital Media (Lawlor, Marshall \& Tangney, 2016), Cross curricular (Sullivan, Marshall \& Tangney, 2015), Computer Science (Byrne, O’Sullivan, \& Sullivan, 2017; Tangney, Oldham, Conneely, Barrett \& Lawlor, 2010), History (O'Donovan, McCrea, Gallagher \& Tangney, 2016) and 
Teacher Professional Development (Girvan, Conneely, \& Tangney, 2016; Byrne, Fisher \& Tangney, 2015; Conneely, Girvan, Lawlor \& Tangney, 2015).

Research has shown it to be effective in increasing student motivation and developing their confidence in a range of skills (Lawlor et al., 2016). Students working in the Bridge21 learning space took increased responsibility for their learning and showed an improved ability to learn with and from their peers. Student surveys, carried out using an adapted version of the Ravitz et al. (2012) 21C skills framework, showed that students who had spent four days taking part in Bridge21 workshops reported large increases in confidence in all six skill categories (Sullivan, Kearney, O'Kelly, \& Tangney, 2017). Increases in similar skills were reported when the model was deployed within the formal education system (Johnston et al., 2014).

This chapter shares the practical facilitation strategies that are usually left out of research papers, which favour the reporting of data. Throughout this chapter, each element of the Bridge21 learning model is introduced in theoretical terms, followed by a facilitator's guide to that element. These elements can be considered the "ingredients" or "what is" necessary for a successful Bridge21 learning experience. After that, the chapter explores the Bridge21 Activity model in detail, this can be considered the "recipe" or the "how to" guide for a successful Bridge21 Activity. Combining both the Learning model and the Activity model should produce an effective $21^{\text {st }}$ Century learning experience.

Fig. 1 The Bridge 21 Learning Model

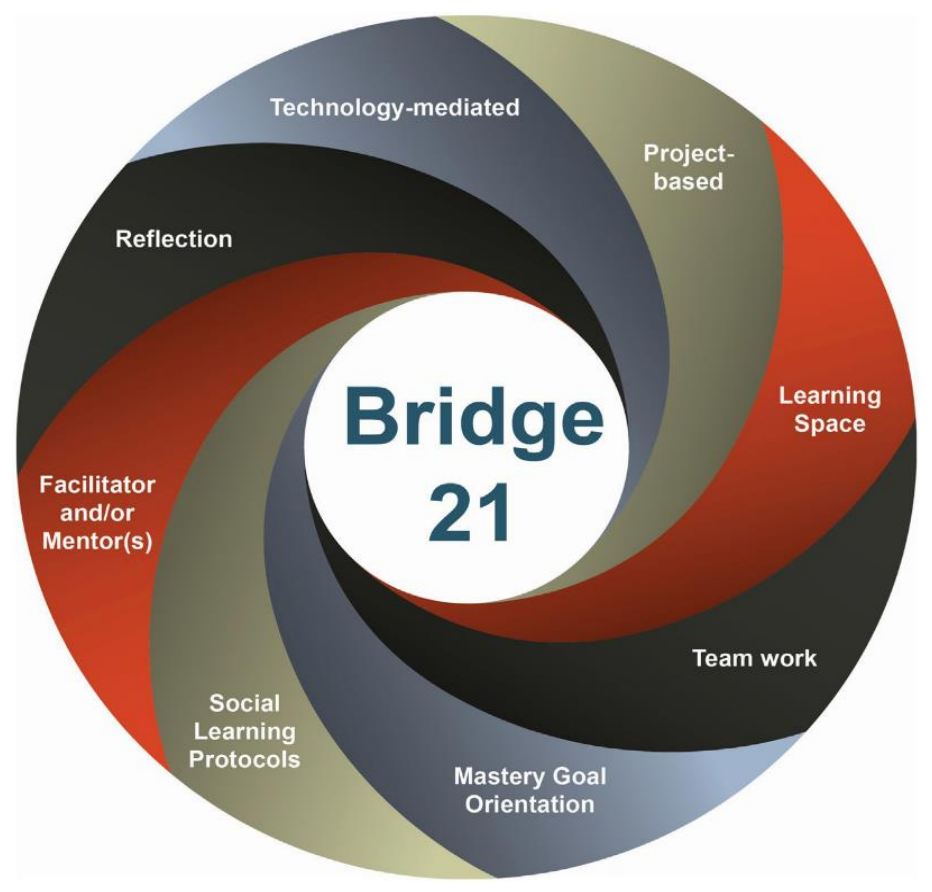

\section{Bridge21 Learning Model in Theory and Practice}

This section describes the theoretical underpinnings for each element of the Bridge 21 Pedagogical Model (Fig. 1.1) and provides practical facilitator guidelines for enacting these elements in a learning experiences. It will demonstrate how the elements of the model link 
together and, when used in combination, can help facilitators create a $21 \mathrm{C}$ learning experience for students.

\subsection{The Facilitator}

The role of the facilitator is central to the Bridge 21 model: the facilitator creates the conditions and environment which allow the students to work and learn together. The facilitator designs the projects/activities/tasks students will complete; sets up the learning space to encourage teamwork and collaboration, project-based learning, technology-mediated learning, and a social learning environment; introduces activities and provides appropriate scaffolds, where necessary, throughout a project; manages the time and keeps teams on task; intervenes in teams, where necessary, to help find solutions to any issues; and leads students in reflecting on their progress and learning. Throughout a Bridge21 learning experience, the facilitator is a supporter, guide and co-learner; s/he acts as a "guide on the side" (King 1993), helping the students to work throughout a project, yet allowing students to lead their own learning process.

\subsection{Team Work}

Teamwork is central to the Bridge 21 pedagogical model. The model is based on a Vygotskian social constructivist perspective to learning, where students learn from each other (Lawlor et al. 2018). Vygotsky's idea of the Zone of Proximal Development (ZPD) positions learning in a space where, with help from others, the learners can learn new things not possible on their own (Vygotsky 1978). ZPD is an approach that advocates a heterogeneous team where each member can bring their own expertise, whether this is technical/domain knowledge or transferable "soft" skills. This diversity provides each team member to grow individually and contextualise their learning. This means that no two learning experiences within that team are necessarily the same.

Building a team, however, is a process that involves establishment, development and nurturing (Katzenbach and Smith 1993). It's the role of the facilitator to select team members and to facilitate, when necessary, in the process of helping the team work together.

\section{Choosing a team:}

Adhering to Michaelsen \& Sweet's (2008) recommendation, the facilitator chooses students for each team, in order to ensure diverse teams and to avoid students' previous interpersonal relationships getting influencing the team dynamic. If the facilitator is familiar with the group of students, some recommended guidelines to follow, where appropriate, are:

- Teams of 4-5 students

- Mixed gender groupings

- Mixed ability groupings

- Mix students from different classes or schools

- Pair students with Special Educational Needs a trusted or responsible peer

- Place 'leaders'/forthright personalities on different teams 
If a facilitator is meeting a group for the first time and has no other information about them, one simple strategy (to form five teams) is to give each student a number between one and five. The students with matching numbers should be in the same team. The idea is that students are likely to sit beside their friends or students they know. This method is fair and transparent in the eyes of the students but creates teams that are well mixed.

\section{Team Roles:}

In the Bridge 21 model, all teams have a leader, chosen at the start of the learning intervention by the other members of the team. The team leader system allows the students to take ownership of their work in a way that would not be possible with direct interventions from an adult. A clear understanding of what the role entails will allow students to feel comfortable volunteering to take on the job or to decide which of their team-mates might make a good leader.

These responsibilities can include:

- Being a link between the team and the facilitator

- Encouraging everyone to contribute, keeping the team positive

- Keeping the team on task and communicating with each other

- Ensure everyone understands what is expected of them

- Supporting their team-mates

With a younger or less experienced group, the expectations of the leaders will be fewer. As students become more capable, the leaders can take on more responsibility in terms of managing their team-mates, assigning or coordinating roles and scheduling the project work.

The facilitator regularly communicates with the team leaders to discuss their progress on their projects and to make decisions. These meetings allow the facilitator to keep track of progress, discuss anything they noticed while the students are working and share problems and solutions found in one team with the other leaders.

In addition to the team leader, the facilitator may choose to designate roles to the other members of the teams - usually this is done with a younger group or students less accustomed to teamwork/the Bridge 21 model. The roles can, for example, include: timekeeper or researcher.

\section{Developing and Nurturing:}

The same teams are maintained throughout the Bridge 21 learning activity/intervention to allow the teams to develop. The facilitator should be available to intervene and help resolve any issues that arise; however, they should encourage the teams to attempt to find solutions to their problems before seeking external intervention (Lawlor et al., 2018).

If intervention is needed, sometimes a brief discussion with the team, while they work, will suffice. If the team is fractured (e.g. two pairs of students working separately) it may be useful to speak to the team leader alone to find out if there is a problem. A team meeting with the facilitator might help get them back on track. The facilitator can also raise an issue, without addressing any individuals directly, by speaking to the whole group before or after a break. 
Though the facilitator aims to foster team independence, it is important for the facilitator to observe team dynamics and progress throughout the project cycle. The facilitator can move from team to team, checking in, asking questions, helping to solve problems and generally guiding the teams though the process.

\subsection{Project Based Learning}

The Bridge21 model involves project-based learning (PBL): teams are challenged to complete projects that test and develop the team, and ultimately help students develop various key skills. Bridge 21 utilises a common understanding of a project-based learning approach: projects should be both challenging and complex, require collaboration among team members, have time limits, and be situated in authentic, real-world scenarios (Savery \& Duffy, 1995). The use of ICT is also a common element in contemporary PBL, and is utilised in the Bridge 21 model, as well, which will be further explained in the following section. Moreover, the projects require the production of an artefact, presentation of the artefact, and a reflection component (Lawlor et al., 2018). This concepts of PBL and teamwork in the Bridge 21 model go hand-in-hand. The projects should be complex enough to appropriately challenge a heterogeneously mixed team of students, providing opportunities for students with different skill levels to both thrive and learn something new and ideally to teach the other team members along the way. The projects should also be complex enough so that one person cannot take the lead and complete the project on his/her own; teams must distribute tasks and set deadlines in order to produce their artefact. Typical artefacts include short videos, edited audio recordings, computer programs or presentations.

The facilitator's role is to design the project and to support (but not necessarily direct) students in completing it (Thomas, 2000). In designing the projects, it is recommended to keep the "SMARTER" acronym in mind: the project and it goals should be Specific, Measurable, Attainable, Relevant, Time-bound, Engaging, and Recordable (Lawlor et al., 2018). They should be team-oriented and scaffolded when and where necessary.

Providing the right amount of scaffolding for a group for any given task relies on the judgement on the facilitator and their knowledge of both the topic and their students. The facilitator will provide guidance to the teams as they work and model what they see as best practice and approaches to project work at the various stages of the process. For example, in early projects the facilitator might choose the type of artefacts they will create as part of their project, such as a sound recording or a movie. As students progress, the focus can shift so that the facilitator allows students to choose the artefact they create, encouraging them to think about the message they want to communicate and choosing the medium which best achieves this.

As the students are working, the facilitator can guide them, help them solve problems and highlight things they may have missed. Students should be encouraged to try things for themselves and to ask their team-mates for help. The facilitator should help the students find the answers they need rather than immediately telling them or doing it for them. The facilitator may also need to intervene by setting intermediate deadlines in order to help students manage their time, especially on a more complex project, and to keep students on schedule. 


\subsection{Technology Mediated}

In the Bridge 21 model, technology is an integral tool in mediating the learning process. This draw inspiration from Vygotsky's (1978) idea where activity can be mediated by sign and tools. The tools of technology, can take a variety of forms - from something as simple as a whiteboard and markers, to a guiding worksheet, or to a video camera and editing software. It is designed to leverage current technology and to release its potential through a structured move away from individualised, teacher-led learning.

Somewhat paradoxically, "technology is both integral and ancillary...[the use of ICT] is not in itself the object of the learning but their use is central to the model" (Lawlor et al., 2018, p. 6). Indeed, the emphasis is not placed on developing enhanced ICT skills, but rather on learning key skills and subject content.

The facilitator must choose the technology students will use throughout the activity and/or to create their artefacts; the choice will often be limited by the resources available. It is recommended to design activities that utilise the technology in an authentic way - as it's used in the real world (which also supports the development of the project-based learning concepts). It is also recommended that students share resources; it is typical in Bridge 21 experiences that a team of four of five members has two-three devices. In this way, team members are encouraged to share, collaborate and teach one another, thus strengthening their team and learning important collaboration skills.

The facilitator is available to guide students and help them learn to use different technologies or certain features of a piece of technology. Choosing the right level of scaffolding here will depend on the students themselves and the complexity of the technology being used. The Bridge21 approach usually involves minimal introductory instruction and 'light touch' guidance (Wu, 2002). For example, the students may be tasked with making a short video. If the software is relatively user-friendly, they could be told that editing software is available and there may be a short discussion about the basic functionality. They would not receive any instruction on how to use it. If the software is more complex, a brief overview or introductory video, for example, can help establish some base skills. Essentially, the aim is that students have a chance to explore the new technology or applications themselves; they can learn with and from one another as they discover the possibilities and potential of new software (Mitra \& Quiroga, 2012).

\subsection{Mastery Goal Orientation}

Bridge 21 aims to encourage participants to do their best - rather than establish whom among the group is the best. This element emphasises that the development of key $21 \mathrm{C}$ skills and subject content knowledge for all students, but places the value on the growth in individuals' skills and the effort involved in the learning (Lawlor et al., 2018). It favours a 'mastery' goal orientation, which values developing competencies, and disfavours a 'performance' goal orientation, which aims to establish superiority over others (Chiaburu, 2005). Thus, Bridge21 promotes "an assimilation of skills rather than a normative performance based approach" 
(Lawlor et al. 2016), recognising the need for differentiated teaching and learning, which supports progress made rather than a particular objective outcome.

The facilitator encourages and challenges each team relative to their own ability and experience; this could be accomplished through the use of the other elements of the model. For example, the Bridge 21 model of teamwork supports the tailored development of key skills and content knowledge, as students are encouraged to learn from each other. The concepts of the "more-able other" and peer-learning is particularly important here, as students are encouraged to help their team members develop the skills they need to complete a project, and in the process develop their own skills. There may be a natural tendency for teams to compete, but instead the facilitator encourages teams to help, support and applaud each other and to even constructively critique one another to encourage an atmosphere of 'inter-team cooperation' (Lawlor et al., 2018). There is no competition or prizes awarded to teams, as the idea is that each team's level achievement and success will look different.

The design of the learning activity should allow scope for some teams to take on greater challenges than others. Project-based learning can provide a rich context and allow for differentiation, as a complex activity would require a variety of skills: students can work to improve upon skills they have, teach others skills, and/or develop new skills. Differentiation can be provided through setting varied goals for each team or by providing scaffolding, depending on the needs of each team. This might include a printed resource, a video or website or simply some guiding questions or advice. Furthermore, the tools for learning that the facilitator selects use of technology should support this idea of mastery goal orientation; the technology tools used in the Bridge21 approach have a "low-floor" but a "high-ceiling;" in other words, the tools are not too complicated for beginners to use, but they are sophisticated and have high potential for more experienced users to still learn new skills.

\subsection{Social Learning Environment}

To support the social constructivist pedagogy underpinning the Bridge21 approach, effort is made to create a social learning environment (Blatchford et al., 2003; Dangel \& Guyton, 2003), one in which people collaborate to learn together (peers, mentors and facilitators). The aim is to create an atmosphere underlined by trust, respect, and personal responsibility (rather than policing and control), in which learners feel comfortable and motivated to engage in challenging activities. To create such an environment, a certain level of social informality, as compared to a typical formal school classroom, is desired.

A facilitator aims to build a rapport with students based on trust and respect. For example, students usually call adults mentors/facilitators by their first names; this is to emphasise the idea that the adults are co-learners in this process and that the learning is truly student-led. Moreover, the noise level in a Bridge 21 activity may be higher than the typical instructor-led class, as learners are constantly communicating with each other/the facilitator. These efforts can help maintain a respectful environment while allowing the students the space to think and speak for themselves.

The facilitator's use of the other elements of the Bridge 21 model also contribute to creating a friendly atmosphere, where participants feel comfortable and encouraged to learn together. 
Teams are also encouraged to build rapport (and a level of informality/comfort) by participating in icebreakers/team-building activities, determining a team name, establishing guiding principles to work by, and identifying a leader/particular roles. Using a project-based approach also fosters a social learning environment, as team members must collaborate to complete the project within the given time-frame. The projects are complex enough that multiple participants are needed to complete them but open-ended enough that students' voices and interpretation can move the project in different ways. The shared use of technology also can support a social learning environment. Finally, a mastery-goal orientation philosophy is designed to support a social, supportive learning environment; the facilitator praises students for assisting each other in developing new skills, rather than singling out individuals or teams for achieving an objective marker of success.

\subsection{Learning Space}

In the Bridge 21 model, the physical learning space is flexible: it's designed and configured to support team-based, collaborative learning, as well as the different tasks and activities involved in completing a project. In a collaborative learning environment, the furniture is arranged so that students can easily and comfortably work together, share resources and interact. This can include dedicated learning spaces for each team, so the students can feel a certain amount of ownership of and privacy within their working area. For example, in the Bridge21 learning laboratory, there are partitioned learning spaces called 'team pods,' equipped with PCs, desks, and swivel chairs (Lawlor et al., 2018). The Bridge21 laboratory also has an open space for conducting plenary sessions, where the whole class/group can come together to, for example, complete warm-up activities, discuss key aspects of the project, and present their projects.

The facilitator organises the learning space to support the implementation of the Bridge 21 learning model. A designated area for each team helps solidify the group and their working relationships: they share and take 'ownership' of their space. These 'pods' or team spaces give teams the opportunity to work comfortably, semi-privately and collaboratively to complete their project. As teams work in designated areas, it's essential that the space also allows the facilitator to move freely between groups to monitor progress. Within their learning space, teams are also only given a limited number of devices to encourage the technology-mediated approach used in the Bridge 21 model. Furthermore, social learning protocols are reinforced through the learning space; students are trusted to be respectful of the space and to move freely within it. The facilitator fosters student-led learning, as students are given the space, as well the tools, to complete their projects in their own way.

\subsection{Reflection}

Finally, students' reflection is a key element of the Bridge 21 model and should be included as a regular part of learning activities. Students can reflect both in teams and individually. Team reflection serves the purposes of building and strengthening the team (Hills, 2001). Individual reflection on one's own learning and progress is also beneficial as it can help develop 
understanding, aid meta-cognition and cement learning (Dewey, 1933; Kolb, 1985). The reflection process allows students to think about their learning, but also helps a facilitator to see where students feel they are thriving or struggling. This information can support activity planning or facilitating the students through subsequent projects.

It is ideal for students to have some quiet, semi-private space to think and reflect. Structured questionnaires can help guide students in reflecting on how well they are collaborating and what challenges they are facing. Individuals can be encouraged to reflect on their development of key skills/content knowledge and/or the personal experience in general. This reflective approach supports the mastery goal orientation of the Bridge 21 model, as facilitators and students have the opportunity to assess their progress and attainment of individualised learning goals.

Fig. 2 The Bridge21 Activity Model

\section{Bridge21 Activity Model}

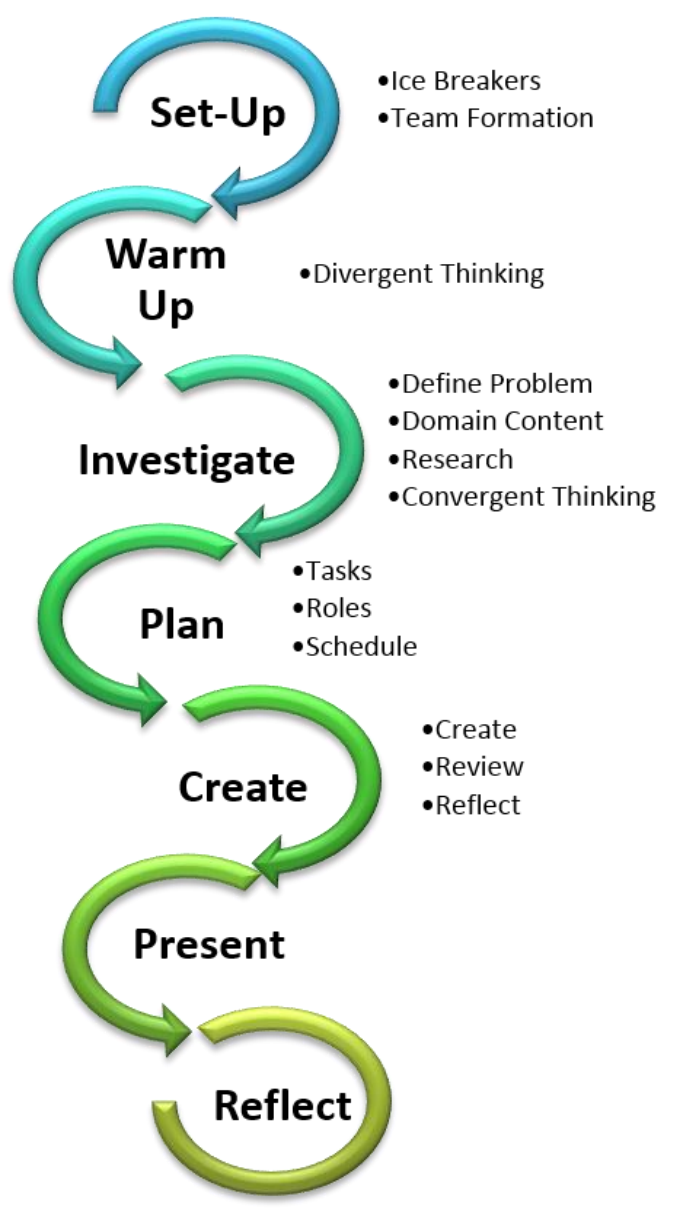

This section explores the Bridge21 Activity Model phases and steps in detail, see figure 2. We explain the motivation for each step, what is involved, what resources are needed, and whether it is optional or recommended. We also outline the key competencies and 21 st Century learning skills that are catered for in each step. The following details are generic in nature, but can easily be adapted to a wide range of activities. 


\subsection{Set-up}

This initial phase can include a number of different activities, depending on whether this is the first time the group is working with each other or the teacher. Some of the activities may be skipped if the group has lots of prior experience working together and/or in teams, but are recommended if the group is not familiar with each other and for groups new to teamwork.

These activities focusing on developing team dynamics and are important if a group is not familiar with each other or if they are not experienced in working in teams. It is also where teams are formed and they start thinking creatively about the topic that the activity will focus on.

\section{Ice breaker}

This step is especially important for groups who don't know each other or if there is low energy in the room (e.g. early morning or late afternoon classes). Ice-breaking activities ${ }^{1}$ usually involve sharing personal information such as names, hobbies, etc. and/or an active game which has people on their feet and moving around. This helps in the development intra group communication and a precursor to effective team communication.

○ Optional: usually for new classes, groups not familiar working together.

○ Technology and Resources: Ice Breaker Plan and associated resources

○ Skills: Collaboration skills, Communication skills

\section{Team Selection/Formation}

As discussed above, teamwork is essential to the Bridge21 approach to learning. It is recommended that the facilitator put the students into their teams in order to make sure that they are mixed-gender/ability. This usually involves the team getting to know each other, deciding on a team name, developing a set of guiding rules (can help them resolve conflicts later) and select a team leader (this can be temporary if they don't know each other well). See section 2.2 above for more details.

O Optional: only required if new teams need to be formed

- Technology and Resources: Paper or whiteboards and pens

○ Skills: Collaboration skills, Communication skills

\subsection{Warm Up}

\section{General Divergent Thinking Activity}

Once the teams are formed, their first task is a general divergent thinking activity (e.g. 30 things to do with a paperclip/orange). This helps the teams warm up and start to develop a working relationship while also getting them to think creatively. It is important to monitor the team's

\footnotetext{
${ }^{1}$ Examples here: http://tft-project.eu/index.php/set-up-activities/
} 
progress with this task making sure that everyone is engaged and contributing. This activity sets the precedent for the team's behaviour in the following tasks and activities making it crucial to encourage full participation.

$\circ \quad$ Optional: encouraged for groups who need to relax and need to get into a creative mode of thinking.

○ Technology and Resources: paper, pens, whiteboards, markers, scissors, or online tools such as realtimeboard.com or padlet.com

○ Skills: Collaboration skills, Communication skills, Creativity and Innovation.

\subsection{Investigate}

This phase is the preparation for the main activity and is recommended for every Bridge 21 activity. It sets up the problem/context of the activity or lesson to follow. It provides the opportunity for teachers to loosely define the problem area, leaving enough scope for the teams to develop their own perspective on the problem and thus make the problem their own.

The investigate phase usually starts by defining the problem context followed by ideation and some optional research. Ideally this phase elicits students' prior knowledge of the topic or context, helping them to identify with the content or problem.

\section{Problem Context / Brief}

The teacher outlines the activity by explaining the activity brief or problem context. A balance should be made between making it clear to the students what they have to do, but leaving enough scope that they can take ownership and tackle the topic in a creative manner.

\footnotetext{
- Recommended

- Technology and Resources: Can depend on topic/context. Usually revolves around multimedia presentation material, but may simply be delivered orally.

○ Skills: Communication skills, Critical Thinking.
}

\section{Divergent Problem Thinking}

Whole team engagement in the stage is essential. The divergent thinking is a useful stage to elicit students' knowledge around a given topic. This can be useful for two reasons. The first is that it helps students identify prior knowledge related to the topic. The second is it can give the facilitator an insight into how well the students understand the topic and how much additional scaffolding might be need later. This might affect whether the next two steps (Content Knowledge Development and additional research) are required, or not. It also provides the teams and wider group to explore and think laterally about the problem. It is important that the student "thinking outside the box" in a playful manner, as this affects how students share and contribute ideas throughout the activity. 
○ Recommended

○ Technology and Resources: paper, pens, whiteboards, markers, scissors, or online tools such as realtimeboard.com or padlet.com

○ Skills: Collaboration skills, Communication skills, Creativity and Innovation.

\section{Content Knowledge Development Exercise}

This optional stage might be required if more content/domain knowledge or experience in skills needed during the main activity. This can entail the use of exercises or mini-activities to develop the necessary knowledge and/or skills. For example an activity might elicit a number of questions that then might be used in the research stage that follows or it might be appropriate to offer direct instruction.

$\circ \quad$ Optional: Beneficial when the teams have very limited knowledge of the problem context.

- Technology and Resources: Can depend on topic. Should be activity based where possible, but may include delivery using multimedia material.

○ Skills: Collaboration skills, Critical Thinking, Self-direction skills.

\section{Research}

As an alternative to direct instruction, this optional stage is useful for training teams in best practices in how to access and evaluate content and materials. Through this process the teams can learn more about the problem space and can explore the ideas that emerged from the divergent problem thinking stage.

$\circ \quad$ Optional: Beneficial when the teams have very limited knowledge of the problem space.

- Technology and Resources: Pen and paper, computer/device with internet connection, word processor for note taking, webquest for scaffolding

○ Skills: Learning with Technology, Critical Thinking, Self-direction skills.

\section{Problem Refinement/Framing/Design}

For this phase the objective is for the teams to focus and refine their problem context so that they have a clear, self-directed, idea about what they are going to do. It is good practice for the teams to consider at least three potential directions/topics and critically analyse them before they choose the direction/topic they consider the most interesting and plausible/practical considering the time and resource constraints they will have for this activity.

- Recommended

- Technology and Resources: paper, pens, whiteboards, markers, scissors, or online tools such as realtimeboard.com or padlet.com

○ Skills: Communication skills, Creativity and Innovation, Critical Thinking. 


\subsection{Planning}

The planning phase provides an opportunity for the teams to develop their project management and organisation skills. The goal is to develop a plan of action through the development of a comprehensive list of tasks, a timeline or schedule and a breakdown of roles and tasks assigned to each team member.

\section{Develop Task List/Outline}

For this stage the team should decompose or break down the larger project into a set of smaller tasks. The facilitator can scaffold the activity through the use of templates (e.g. using a storyboard sheet and crew roles templates for video production). The goal here is to have the teams take ownership of the activity, thinking pragmatically about how they are going to complete the task.

○ Recommended

$\circ \quad$ Technology and Resources: Paper, pens, templates, word processor, or online tools such as realtimeboard.com or padlet.com

○ Skills: Collaboration skills, Critical Thinking, Self-direction skills.

\section{Task, Role, Scheduling, Resource Assignment}

Once a list of task has been developed the teams need to consider who will complete the task, what resources will be need and how long/when does it need to be completed by. This can either be scaffolded by the facilitator, using templates/worksheets, for inexperienced groups or alternatively they may be can develop their own templates, guided by the facilitator. Tasks, roles and resources are then assigned to to individual team members (multiple team members can collaborate on tasks, but a single individual should be encouraged to make sure that the task is completed).

- Recommended

$\bigcirc \quad$ Technology and Resources: Templates, Paper, Pen, word processor. For longer projects, task management tools such as Trello.com or Slack.com might be useful.

○ Skills: Collaboration skills, Communication skills, Self-direction skills.

\subsection{Create/Execute}

The main activity can see the teams work through a number of iterations of execute, review and reflect. Throughout this phase the facilitator and team leaders should meet regularly (every 20-50 minutes, depending on activity duration) to review their progression, and reflect on any issues that might have arisen. If the activity or lesson permits these steps can be repeated, this can involve iterations that might refine their work before completion. 
In the create/execute step the teams plan is put into action. Where possible, time should be made available to revise their plan.

- Recommended

$\bigcirc$ Technology and Resources: depends on activity (pen, paper, whiteboard, camera, computer, video editor, Scratch, Python, micro:bit, Raspberry Pi etc.).

○ Skills: Learning with Technology, Collaboration skills, Self-direction skills.

\section{Review/Evaluate/Test}

Reviewing and evaluating the progression of the teams plan is critical for success. During this step the teams review their progress and update their plan and tasks if required. This can either be achieved within the team or facilitated by the facilitator through the team leaders.

- Recommended

$\circ \quad$ Technology and Resources: Paper, pen, review template (sample or teacher created), task list/task management tool.

○ Skills: Communication skills, Critical Thinking, Self-direction skills.

\section{Reflection in action}

Reflection during the activity is important, this can be achieved either through the use of explicit worksheets or through Socratic questioning by the facilitator. The flexibility of the questioning approach is useful when trying to get a student who is struggling to reassess their engagement and approach by reflecting on their teamwork and overall contributions to the project.

○ Recommended

○ Technology and Resources: Review template (paper based or digital).

○ Skills: Communication skills, Critical Thinking, Self-direction skills.

\section{Iterate/Repeat (if there is time available)}

If there is time available the team should return to the execute/create step. This allows the team to either continue as they were, work on a revised plan or refine their output for presentation. If allocated time does not permit another execution phase, the teams should move onto the next presentation step.

\subsection{Present}

The finale is the final and essential phase of the activity. Teams present their work to the whole group, reflect both individually and in teams on their learning experience and feedback any comments or observation in a whole class discussion.

Presentation play a crucial role in the activity model as it develops important communication skills and confidence with public speaking. The whole team should contribute to the presentation 
and they should describe both the final artefact and what role each team member played in completing the activity.

- Recommended

○ Technology and Resources: Digital projector, computer, whiteboards.

○ Skills: Communication skills, Critical Thinking, Self-direction skills.

\subsection{Reflection on action}

Reflection on action can take two forms, in teams and individuals reflection. This is usually best achieved through a scaffolded and structure worksheet. It should focus on how well they worked together and what they personally got out of the experience and what they might like to improve on next time.

○ Recommended

$\bigcirc \quad$ Technology and Resources: Reflection template (paper based or digital).

○ Skills: Communication skills, Critical Thinking, Self-direction skills.

\section{Whole group discussion}

The final step is to provide an opportunity for a whole group discussion. This provides a space where, based on their reflections, students may share what they learnt, found difficult, enjoyed or would recommend doing differently if the activity was to be repeated. This is also a good opportunity for the facilitator to get some insight into how the activity went overall and might provide some feedback on how to improve the activity should it be repeated again.

$\circ \quad$ Recommended

○ Skills: Communication skills, Critical Thinking.

\section{Summary and Conclusion}

As discussed in the introduction of this chapter, educational theory can be heavy on the academic rigor, but can have limited or less obvious practical examples that educators can directly apply to the design of technology-mediated learning experiences for their students (Bruenig, 2005; Conneely, Lawlor, \& Tangney, 2013; Donnelly, McGarr \& O'Reilly, 2011). This chapter explained in detail the various elements which comprise the Bridge 21 approach to 21st Century teaching and learning, as well as a step-by-step activity model and guide for planning and implementing the approach in formal or informal educational settings. The chapter represents a fusion of academic theories and practical experience gathered over the last 10 years by the Bridge 21 programme team. The model has been used effectively in a wide range of contexts and with various groups of students and it has been developed and refined over the course of this time. Research into the use of the approach has consistently demonstrated an improvement in students motivation in learning (Lawlor et al., 2016) and an increase in confidence in key 21C 
skills such as learning with technology, communication, critical thinking, and self-directed learning (Sullivan et al., 2017; Johnston et al., 2014).

A practical approach is an important step to implementing technology-mediated, 21C learning experiences in the classroom, yet education systems require development in a number of areas in order to fully support educators in adopting such practices in their teaching. For example, teachers need more professional development and training (Donnelly et al., 2011), particularly involving experiential learning with this type of model. From the authors' experience of working with teachers in a variety of contexts, it is clear that teachers need the opportunity to learn within the model, experiencing first-hand the skills and content knowledge one can develop whilst engaging in this approach. Moreover, teachers need professional development to help them develop their understanding of how to teach curriculum content, as well as key skills, through a technology-mediated approach such as Bridge21. As the old adage goes, "you teach as you've been taught." Thus, educational administrators — at the school and state level — need to provide teachers with the opportunity and funding for quality professional development to help them fully realise and integrate the Bridge21 approach into their classrooms.

Moreover, policy-makers and curriculum writers need further alignment with $21 \mathrm{C}$ teaching and learning approaches. Without the support and alignment with policy and curriculum content this type of learning model, which has shown to be powerful and effective among students in a variety of areas, will remain on the fringes. Related to this area, educators need guidance in terms of assessment and determining how one can assess students using such an approach. For example, there exists questions around summative vs. formative assessment, evaluating teams vs. individuals, and awarding the best performance compared to the rest of the group vs. mastery of skills and individual progression by each student; these are subjects of much debate, as internationally, educators are trying to determine how best to assess 21C skills (Geisinger, 2016; Griffin, Care \& McGaw, 2012). It is challenging for classroom teachers to implement a 21C approach to learning, when they are still required to evaluate students based on a system linked to a more traditional approach to teaching and learning.

Despite these challenges faced by educators, through this chapter, the authors hope that the detailed practices outlined offer a balance of both theory and practice, and thereby fulfil a need, as highlighted in the literature, for a practical approach and guidelines for implementing an effective technology- mediated, 21C teaching and learning approach in the classroom. Over the past ten years, the authors have seen the Bridge 21 model used in a variety of contexts and accommodate new technologies which have emerged. Moving forward, the authors believe the model will continue to be flexible and can adapt to new contexts/technologies, continuing to be a powerful model for teaching and learning.

\section{References}

Ananiadou, K. \& Claro, M. (2009). 21st century skills and competences for new millennium learners in OECD countries. OECD Education Working Papers, No. 41, OECD Publishing.

Blatchford, P., Galton, M., Kutnick, P., \& Baines, E. (2003). Toward a social pedagogy of classroom group work. International Journal of Educational Research, 39, 153-172. 
Bray, A., \& Tangney, B. (2016). Enhancing student engagement through the affordances of mobile technology: a 21st century learning perspective on Realistic Mathematics Education. Mathematics Education Research Journal, 28(1), 173-197.

Bruenig, M. (2005). Turning experiential education and critical pedagogy theory into practice. Journal of Experiential Education, 28(2), 106-122.

Byrne, J. R., Fisher, L., \& Tangney, B. (2015, October). Empowering teachers to teach CSExploring a social constructivist approach for CS CPD, using the Bridge 21 model. In Frontiers in Education Conference (FIE), 2015 IEEE (pp. 1-9). IEEE.

Byrne, J. R., O’Sullivan, K., \& Sullivan, K. (2017). An IoT and Wearable Technology Hackathon for Promoting Careers in Computer Science. IEEE Transactions on Education, 60(1), 50-58.

Chiaburu, D. S. (2005). The effects of instrumentality on the relationship between goal orientation and leader-member exchange. The Journal of Social Psychology, 145, 365-367.

Conneely, C., Lawlor, J., \& Tangney, B. (2013). Technology, Teamwork and 21st Century Skills in the Irish Classroom. In K. Marshall (Ed.), Shaping our Future: How the lessons of the past can shape educational transformation. Dublin: Liffey Press.

Conneely, C., Girvan, C., Lawlor, J., \& Tangney, B. (2015). An exploratory case study into the adaption of the Bridge21 Model for 21st Century Learning in Irish Classrooms. In K. Marshall (Ed.), Shaping our Future: How the lessons of the past can shape educational transformation, 348-381. Dublin: Liffey Press.

Dangel, J., \& Guyton, E. (2003, January). Expanding our view of teaching and learning: Applying constructivist theory (s) to teachers' education. Paper presented at the Annual Meeting of the American Association of Colleges for Teacher Education, New Orleans, LA.

Dede, C. (2007). Transforming education for the 21st century: New pedagogies that help all students attain sophisticated learning outcomes. Commissioned by the NCSU Friday Institute, February.

Dede, C. (2010). Comparing frameworks for 21st century skills. In J. Bellanca \& R. Brand (Eds.), 21st century skills: Rethinking how students learn (Vol. 20, pp. 51-76).

Dewey, J. (1933). How we think: A restatement of the reflective thinking to the educative process. Boston, MA: D. C. Heath and Company.

Donnelly, D., McGarr, O., \& O’Reilly, J. (2011). A framework for teachers' integration of ICT into their classroom practice. Computers \& Education, 57(2), 1469-1483.

Fullan, M \& Langworthy, M. (2013) Towards a new end: New pedagogies for deep learning. Seattle WA: Collaborative Impact.

Geisinger, K. F. (2016). 21st Century Skills: What Are They and How Do We Assess Them? Applied Measurement in Education, 29(4), 245-249. 
Griffin, P., Care, E., \& McGaw, B. (2012). The Changing Role of Education and Schools. In P. Griffin, B. McGaw, \& E. Care (Eds.), Assessment and Teaching of 21st Century Skills (pp. 1-15). Dordrecht: Springer.

Girvan, C., Conneely, C., \& Tangney, B. (2016). Extending experiential learning in teacher professional development. Teaching and Teacher Education, 58, 129-139.

Hills, H. (2001). Team-based learning. Farnham: Gower Publishing Company.

Johnston, K., Conneely, C., Murchan, D. \& Tangney, B. (2014) Enacting key skills-based curricula in secondary education: lessons from a technology-mediated, group-based learning initiative. Technology, Pedagogy and Education, 24:4, 423-442.

Katzenbach, J. R., \& Smith, D. K. (1993). March-April). The discipline of teams. Harvard Business Review, 71, 114-146

King, A. (1993) From Sage on the Stage to Guide on the Side. College Teaching, Vol. 41, No. 1 (Winter, 1993), pp. 30-35.

Kolb, D. A. (1985). Learning styles inventory: Technical manual. Boston, MA: McBer and Company.

Lawlor, J., Conneely C., Oldham E., Marshall, K., \& Tangney, B. (2018): Bridge21: teamwork, technology and learning. A pragmatic model for effective twenty-first-century team-based learning. Technology, Pedagogy and Education.

Lawlor, J., Marshall, K., \& Tangney, B. (2016). Bridge21-exploring the potential to foster intrinsic student motivation through a team-based, technology-mediated learning model. Technology, Pedagogy and Education, 25(2), 187-206.

Michaelsen, L., \& Sweet, M. (2008). The essential elements of team-based learning. New Directions for Teaching and Learning, 2008(116), 7-27.

Mitra, S., \& Quiroga, M. (2012). Children and the Internet. A preliminary study in Uruguay. International Journal of Humanities and Social Sciences, 15, 123-129.

O'Donovan, D., McCrea, J., Elena Gallagher, S., \& Tangney, B. (2016). Living The Lockout: The Dublin Tenement Experience Participation Design for Locals, Diaspora, and Teenagers through Engagement with one of the Darkest Times in Dublin's History. Museum International, 68(3-4), 131-147.

Piaget, J. (1964). The Early Growth of Logic in the Child. London: Routledge and Kegan Paul Ltd.

Ravitz, J., Hixson, N., English, M., \& Mergendoller, J. (2012, April). Using project based learning to teach 21st century skills: Findings from a statewide initiative. In American Educational Research Association Conference, Vancouver, Canada (Vol. 16).

Rotherham, A.J., \& Willingham, D.T. (2010). "21st-Century” Skills. American Educator. 34. 17.

Savery, J. R., \& Duffy, T. M. (1995). Problem based learning: An instructional model and its constructivist framework. Educational Technology, 35(5), 31-38. 
Silva, E. (2009). Measuring Skills for 21st-Century Learning. The Phi Delta Kappan, 20(9), 630634.

Spiro, R.J., Coulson, R.L., Feltovich, P.J., \& Anderson, D.K. (2004). Cognitive flexibility theory: Advanced knowledge acquisition in ill-structured domains. In R.B. Ruddell \& N.J. Unrau (Eds.), Theoretical models and processes of reading (5th ed., pp. 640-654). Newark, DE: International Reading Association.

Sullivan, K., Marshall, K., \& Tangney, B. (2015). Learning circles: A collaborative technologymediated peer-teaching workshop. Journal of Information Technology Education: Innovations in Practice, 14, 63-83.

Sullivan, K., Kearney, S., O'Kelly, M., \& Tangney, B. (2017). Bridge21 - A pragmatic approach to "21st century" teaching \& learning. Paper presented at the World Conference on Computers and Education (WCCE), Dublin, Ireland.

Tangney, B., Oldham, E., Conneely, C., Barrett, S., \& Lawlor, J. (2010). Pedagogy and processes for a computer programming outreach workshop-The bridge to college model. IEEE Transactions on Education, 53(1), 53-60.

Thomas, J. W. (2000). A review of research on project-based learning. Retrieved from http://www.bie.org/object/document/a_review_of_research_on_project_based_learning

Voogt, J., \& Roblin, N. P. (2012). A comparative analysis of international frameworks for 21st century competences: Implications for national curriculum policies. Journal of Curriculum Studies, 44(3), 299-321.

Vygotsky, L. S. (1978). Mind in society: The development of higher psychological processes. Cambridge, MA: Harvard University Press.

Wang, F., \& Hannafin, M. J. (2005). Design-based research and technology-enhanced learning environments. Educational technology research and development, 53(4), 5-23.

$\mathrm{Wu}$, S. (2002). Filling the pot or lighting the fire? Cultural variations in conceptions of pedagogy. Teaching in Higher Education, 7, 387-395.

Yelland, N., Cope, B., \& Kalantzis, M. (2008). Learning by design: Creating pedagogical frameworks for knowledge building in the twenty-first century. Asia-Pacific Journal of Teacher Education, 36(3), 197-213. 